DOI: $10.17805 /$ zpu.2019.3.14

\title{
Интегральное понимание как способ изучения предельных ориентаций: подход И.Ваха
}

\author{
И. Л. КОЗЛОВА
}

\section{РОССИЙСКИЙ ПРАВОСЛАВНЫЙ УНИВЕРСИТЕТ СВЯТОГО ИОАННА БОГОСЛОВА}

Статья представляет новую интерпретацию методологических условий интегрального понимания Иоахима Ваха (1898-1955). Проблематизация и актуализация осуществлена через рассмотрение ценностных ориентаций и религиозного опыта. Концепт «предельность» представлен в контексте аксиологической парадигмы с учетом религиозного фактора. Предложен термин «предельная ориентация». Сделан прогноз о том, что концептуальная модель интегрального понимания, основанная на методологических условиях И. Ваха, может быть продуктивно использована современной наукой в междисциплинарных исследованиях.

Термин «предельная ориентация» является логическим произведением понятий «религиозная ориентация» и «ценностная ориентация». Предельная ориентация - это состояние тотальной устремленности человека к предельной реальности. Предлагаемый концепт фокусируется на субъективной стороне предельного опыта и может быть использован в религиоведении, социологии, психологии и культурологии.

Интегральное понимание акцентирует внимание на трех базовых феноменах: индивидуальность, сущность ценностного и значимость свободы. Интегральное понимание включает четыре основные компетенции. Первая - это понимание общих предельных смыслов, выраженных в разных языках. Вторая - это умение пользоваться эмоциональным интеллектом. Третья - это способность настроить волю на конструктивную цель. Четвертая - это практический опыт работы с человеческим материалом. 
Ключевые слова: Иоахим Вах; религиозный опыт; ценностные ориентации; предельная реальность; предельные ориентации; интегральное понимание; эмоциональный интеллект; субкультуры; социология религии

\section{ВВЕАЕНИЕ}

И нтегральное понимание является перспективным методом постнеклассического этапа развития науки. Это обусловлено особой информационно-коммуникационной средой, в которой живет современный человек. Аля обработки масс информации требуется междисциплинарный подход, способный интегрировать знания из разных областей и формулировать тезисы, рождающиеся на стыке их полей. В рамках интегральной парадигмы создаются научные теории, например модель К. Уилбера (Wilber, 2007). Однако нельзя сказать, что эта тема полностью раскрыта. Мы обратились к творчеству малоизвестного в России автора, классика академического религиоведения Иоахима Ваха (1898-1955), чтобы представить его взгляд на интегральное понимание.

Концепт «предельность» (ultimacy), встречающийся в научных текстах, употребляется с разными смысловыми оттенками: «предельные фундаментальные цели» (Einstein, 1950), «предельная забота» (Tillich, 1951), «предельная реальность» (Wach, 1951, 1958), «предельные значения человеческого существования» (Красиков, 1998), «предельные смыслы» (Иеонтьев, 1999) и др. Единого мнения относительно трактовки данного концепта пока не выработано. Однако можно выделить смысловые зоны, которые он затрагивает: нормативно-ценностные структуры и религиозный комплекс.

Изучение ценностей как регуляторов поведения является актуальным направлением социально-гуманитарных наук, так как процессы глобализации и трансформации культур активизируют механизмы переоценки систем ценностей. Современные авторы, например Е. В. Буякова, констатируют необходимость нового определения базовых аспектов формирования ценностей (Буякова, 2016: Электронный ресурс). По наблюдениям В. А. Кузьменкова (Кузьменков, 2018: 156), одним из аспектов приверженности к ценностям являются ритуалы. По словам В. И. Аобренькова (Аобреньков, 2011: 9), в эпоху постсекуляризма религия возрождается как «мейнстрим культуры», и ее влияние на жизнь современных людей усиливается. Поэтому изучение роли религиозных аспектов в социокультурной реальности является актуальным и требует разработки особого методологического аппарата.

В нашем исследовании концепт «предельность» рассматривается в контексте аксиологической парадигмы, а также в его связи с религиозным фактором. Проблематизация в работе осуществляется через совместное рассмотрение ценностных ориентаций и религиозного опыта.

Цель работы - проанализировать состав и строение интегральной модели понимания И. Ваха с учетом ее применимости для изучения предельных ориентаций в современных условиях.

Аля достижения цели поставлены и решены три задачи: во-первых, раскрыть содержание понятия «предельные ориентации», выводимого из концепции И. Ваха; во-вторых, наметить контур концептуальной модели интегрального понимания предельных ориентаций, основанной на четырех методологических условиях, предложенных И. Вахом; в-третьих, разъяснить потенциал, заложенный в интегральном подходе И. Ваха. 
ПРЕАЕАЬНЫЕ ОРИЕНТАЦИИ

Концепция И. Ваха - это концепция религиоведческая. Ее ядром является понимание религиозного опыта как опыта встречи с предельной реальностью (ultimate reality). Предельная реальность - это не зависящая от человека объективность, несущая в себе побудительный императив (Wach, 1951: 33; Wach, 1958: 36). Концепт «предельная реальность» во многом наследует свойства «нуминозного» Р. Отто. И. Вах выделяет три базовых аспекта (primary aspects), выражающих нуминозный характер предельной реальности, по которым человек ее опознает (Wach, 1958: 46-48).

Первый аспект - таинственность, инаковость, необъяснимость (mysterium). Второй аспект - движущая сила (dynamic), включающая спонтанность, витальность, креативность, энергию. Третий аспект - величие и сила (majesty and power), выражающие превосходство предельной реальности над всеми известными человеку силами, подконтрольными его уму и возможностям.

Религиозный опыт рассмотрен И. Вахом как опыт тотальный, затрагивающий все аспекты жизни человека. Это опыт мобилизирующий, активизирующий и интегрирующий все элементы его личности. Религиовед ввел четыре формальных критерия для определения религиозного опыта (Wach, 1951: 30-47; Wach, 1958: 27-58). Их смысловая реконструкция и новая интерпретация представлены нами в предыдущей публикации, где для обозначения критериев И. Ваха введены четыре термина: предельный импульс (первый критерий), предельный интерес (второй критерий), предельное усилие (третий критерий) и предельный акт (четвертый критерий) (Козлова, 2018).

И. Вах акцентировался на субъективной стороне религиозного опыта, и именно в этом мы видим потенциал его концепции для применения в современных условиях. Критерии И. Ваха позволяют зафиксировать антропологическую данность, некое человеческое свойство, а точнее, состояние предельности, в котором человек всецело устремлен к тому, что является для него предельной реальностью, т. е. его высшей (предельной) ценностью, фундирующей все его чувства и действия. По принципу соотнесенности с предметом назовем устремленность к предельной реальности «предельной ориентацией».

\section{УСАОВИЯ ИНТЕГРААЬНОГО ПОНИМАНИЯ}

Аля изучения религиозного опыта И. Вах предложил четыре методологических условия интегрального понимания (Wach, 1958: 11-12).

Первое условие - знание языков. По мнению автора метода, оно необязательно, но крайне желательно. Само по себе оно не дает гарантию положительных результатов в изучении религии, но значительно увеличивает шансы ее адекватного понимания. И. Вах обозначает необходимый языковой минимум - возможность сделать перевод ключевых терминов или проверить адекватность их перевода.

Второе условие - адекватное эмоциональное состояние. Под этим И. Вах понимает неравнодушие в эмоциональном плане. Иллюстрирует он это цитатой из Ницше: «Серые холодные глаза не знают ценности вещей» (там же: 12). Предельный религиозный опыт затрагивает все составляющие человека - интеллект, чувство и волю. Поэтому для его адекватного понимания исследователь должен учитывать в комплексе все аспекты целостной личности (total person).

Третье условие - направленность воли на конструктивную цель. Аанное условие, по мнению И. Ваха, является необходимым для тех, кто желает понимать различные типы религиозности. Аалее он отмечает, что простое любопытство или страсть к 
уничтожению того, что отличается от «своего», от «моего», не должны быть ведущими мотивами.

Четвертое условие - наличие практического опыта работы с человеческим материалом. Психолог или социолог, имеющий навык работы с разными людьми и их характерами, темпераментами, социальными группами и религиозными учреждениями, обладает более подходящим для понимания религиозности набором компетенций.

Чтобы понять, чем может быть полезна модель И. Ваха в наше время, посмотрим на нее сквозь призму современных данных.

Первое условие (знание языков) необходимо не только при изучении религиозных традиций, но и при проведении межкультурных исследований ценностей и предельных ориентаций, а также при переводе ключевых терминов, используемых в социологических и психологических опросниках. Как пишет Т. В. Емельяненко, проблема адекватного переноса смыслов обусловлена тем, что при переводе требуется «войти» в другую культуру, чтобы изложить суть переводимого с учетом языковой ментальности (Емельяненко, 2002: 137), а это требует интегрального подхода в понимании. Кроме того, понимание содержания знаков, используемых для обозначения предельных смыслов и ценностей, важно при изучении современных субкультур. Эти социальные образования, по наблюдениям А. В. Комаровой, «считают существующие вещи, явления, ценности и нормы устаревшими и придумывают либо заимствуют извне новое. $<$... $>$ формируют собственное религиозное мировоззрение, зачастую псевдорелигиозное» (Комарова, 2018: 49).

Второе условие (эмоциональная включенность) предполагает использование метода эмпатии. Взаимосвязь ценностной и религиозной сферы изучают религиоведы, социологи, психологи. Например, В. А. Кузьменков видит причину приверженности людей определенным ценностям в сильном чувственно-эмоциональном воздействии, которое оказывают на индивида ритуалы, передающие знание о высшей реальности (Кузьменков, 2018: 156). Следовательно, для адекватного понимания подобных явлений требуется, выражаясь современным языком, активное «включение» әмоционального интеллекта.

Третье условие (направленность воли) представляется нам расширением второго, говорящего о включенности трех элементов личности человека. И. Вах вводит условие, которое качественно конкретизирует направление включения волевого компонента.

Четвертое условие (наличие опыта) на первый взгляд представляется типовым, и не вполне понятно, почему его надо выделять. Однако отметим, что И. Вах оставил свои методологические рекомендации для религиоведов и этим, полагаем, хотел расширить их научный фокус. Кроме того, в его трудах есть мысль о том, что предельный опыт может выражаться не только в религиозных символах, но также и в других видах человеческой деятельности, например в музыке, живописи, литературе, поэзии (Wach, 1958: 35-36). Это дает основание экстраполировать метод И. Ваха значительно шире.

\section{СОВРЕМЕННЫЙ ПОТЕНЦИАА ИНТЕГРААЬНОГО ПОАХОАА И. ВАХА}

И. Вах в своей концепции особое внимание уделял социологическим импликациям религии. Его монография по социологии религии (Wach, 1944) считается классической в данной области. В структуре социологии религии И. Ваха нами выделено несколько направлений (Козлова, 2015: 194-197). Одно из них, затрагивая актуальные проблемы идентификации религиозных поведений и религиозных институтов, связа- 
но с разработкой критериев, определяющих социальные образования как религиозные или нерелигиозные. Построения И. Ваха дают основание для отождествления религиозного и предельного опыта.

Предельный опыт имеет место как в религиозных, так и в нерелигиозных общностях. Предельная реальность - это смыслообразующее начало жизни человека, источник его высших ценностей. Эвристический потенциал подхода И. Ваха заключается в том, что разработанные им критерии представляют собой инструмент, позволяющий определить и измерить поведение человека, обусловленное тем, что является для него предельной реальностью, и здесь на передний план выдвигается проблема понимания.

Бывает, люди не находят взаимопонимания из-за того, что значение и ценность одного и того же объекта или явления для них различны. Как в такой ситуации понять и принять друг друга, сохранив свои ценности, индивидуальность, свободу и не нарушив при этом их же в другом? Полагаем, что следует проявлять должное понимание и уважение к тому, что является для человека предельным. К примеру, если один готов умереть ради утверждения религиозной истины, а другой готов умереть ради жизни любимого человека, то ясно, что ориентированы они на разные высшие ценности и тем отличаются. Однако в обоих случаях имеет место предельная ориентация, т. е. предельная «устремленность к...», и в этом они похожи, и это может стать основой их конструктивного диалога.

Система И. Ваха побуждает задуматься о том, что для человека является предельной реальностью, т. е. источником его предельных ценностей, к чему он готов направить все силы своей жизни, ради чего он готов умереть или отдать все, что имеет, чему он готов посвятить и подчинить всю свою жизнь, что положит в основу своего бытия.

Предельный опыт имеет троичную структуру - объект (предельная реальность), субъект (воспринимающий и действующий), объект (объективация предельного переживания). Если интерпретировать его в русле психолого-социологического подхода, то предельные реальности можно понимать как что-то, что не нуждается в нахождении обоснования, т. е. как сверхличные объекты и цели, которые не могут быть рационально обоснованы, но в этом и не нуждаются (Einstein, 1950: 21-30).

Выявление предельных ориентаций, полагаем, в перспективе может осуществляться путем фиксации объективированных источников предельных импульсов. Можно сделать прогноз, что социальные общности с высоким уровнем предельности содержат в себе мощнейший потенциал, который может быть использован как в созидательных, так и в разрушительных целях, поэтому такие очаги предельности целесообразно обследовать в первую очередь. Психолого-социологическое измерение уровня предельности социальных групп может осуществляться по трем параметрам: сравнение по общему уровню предельности; выявление его динамики; определение скорости и интенсивности изменения предельности за определенный промежуток времени. Интегральный подход И. Ваха может быть полезен при изучении молодежных субкультур, феноменов экстремизма, фанатизма, а также при ведении межкультурных, межрелигиозных и межконфессиональных диалогов.

\section{ЗАКАЮЧЕНИЕ}

Итак, мы вывели из концепции религиозного опыта И. Ваха понятие «предельная ориентация», означающее устремленность к предельной реальности. Чтобы избежать тавтологии, конкретизируем. Предельная ориентация - это состояние тотальной за- 
хваченности и устремленности человека, при котором все его составляющие максимально активизированы и мобилизированы к действию. Этот термин охватывает две смысловые плоскости: религиозные ориентации, в которых есть состояние предельности, и ценностные ориентации, характеризующиеся состоянием предельности. Таким образом, предлагаемый термин - «предельные ориентации» - является междисциплинарным и объединяет научные поля религиоведения, социологии, психологии, культурологии.

Также мы описали и интерпретировали с учетом современных данных четыре условия интегрального понимания, основанного на модели И. Ваха. Во-первых - навык понимания языков в широком смысле. Во-вторых - умение пользоваться не только рациональным, но и эмоциональным интеллектом. В-третьих - способность настроить свою волю на определенную конструктивную цель. В-четвертых - профессиональная деятельность, сопряженная с изучением человека и заботой о нем. Цитируя И. Ваха, «чтобы метод был адекватным предмету, необходимо отдавать должное феномену индивидуальности, сущности ценностного (nature of value) и значимости свободы (meaning of freedom)»(Wach, 1958: 15), выделим основное: индивидуальность, ценностность, свобода.

Мы выявили, что интегральная модель И. Ваха содержит эвристический потенциал, который может быть раскрыт при дальнейшей апробации модели в ходе междисциплинарных исследований, в частности в контексте проблематик социологии религии. Предметом в подходе И. Ваха выступает интегрированная человеческая личность, что требует соответствующего методологического инструмента для учета многоаспектности всех ее составляющих, а также соблюдения принципа уважения к тому, что является для человека предельным.

Выявленная корреляция религиозного и предельного опыта позволяет сделать прогноз о том, что концептуальная модель интегрального понимания, основанная на методологических условиях И. Ваха, может быть продуктивно использована для изучения предельных ориентаций в пространстве информационно-коммуникационной среды современного общества.

\section{СПИСОК АИТЕРАТУРЫ}

Буякова, Е. В. (2016) Теоретические аспекты исследования ценностей [Электронный ресурс] // Научно-методический электронный журнал «Концепт». T. 15. C. 231-235. URL: http:// e-koncept.ru/2016/86947.htm (дата обращения: 14.06.2018).

Аобреньков, В. И. (2011) Ценностно-ориентированная социология: проблемное поле постнеклассической методологии. М. : Академический проект ; Альма Матер. 565 с.

Емельяненко, Т. В. (2002) Проблема перевода социологических терминов: на примере перевода переменных Т. Парсонса // Социологические исследования. № 6. С. 137-142.

Козлова, И. А. (2015) Социология религии Иоахима Ваха // Вестник Московского университета. Серия 18: Социология и политология. № 4. С. 183-200.

Козлова, И. А. (2018) Критерии религиозного опыта в религиоведческой концепции Иоахима Ваха // Религиоведение. №1. С. 103-117.

Комарова, А. В. (2018) Субкультуры в духовной жизни общества: религиозно-нравственный аспект : дис. ... канд. филос. наук. М. 179 с.

Красиков, В. И. (1998) Явь беспокойства (предельные значения человеческого существования). Кемерово : Кемеровский государственный университет. 170 с.

Кузьменков, В. А. (2018) Ритуалы как факторы возникновения ценностей // Социально-политические науки. № 1 (февраль). С. 152-157. 
Аеонтьев, А. А. (1999) Методика предельных смыслов (МПС) : методическое руководство. М. : Смысл. 36 с.

Einstein, A. (1950) Out of My Later Years. New York : Philosophical Library. 282 p.

Tillich, P. (1951) Systematic Theology, Volume 1. Chicago : University of Chicago Press. 307 p.

Wach, J. (1944) Sociology of Religion. Chicago : University of Chicago Press. $x+418$ p.

Wach, J. (1951) Types of religious experience christian and non-christian. Chicago : University of Chicago Press. xvi +275 p.

Wach, J. (1958) The comparative study of religions. New York : Columbia University Press. xlviii +234 p.

Wilber, K. (2007) The Integral Vision. A Very Short Introduction to the Revolutionary Integral Approach to Life, God, the Universe, and Everything. Boston; London : Shambala. 232 p.

Аата поступления: 10.08 .2018 г.

\section{INTEGRAL UNDERSTANDING AS A METHOD OF STUDY OF ULTIMATE ORIENTATIONS: APPROACH BY J. WACH}

\section{L. KOZLOVA}

\section{RUSSIAN ORTHODOX UNIVERSITY OF ST. JOHN THE DIVINE}

The article proposes a new interpretation of methodological conditions of integral understanding by Joachim Wach (1898-1955). The problematization and actualization is realized through consideration of value orientations and religious experience. The concept of "ultimacy" is presented in the context of the axiological paradigm taking into consideration the religious factor. The term "ultimate orientation" is proposed. It is predicted that the conceptual model of integral understanding, based on J. Wach's methodological conditions, can be productively used by modern science in cross-disciplinary research.

The term "ultimate orientation" is a logical multiplication of the concepts "religious orientation" and "value orientation". Ultimate orientation is a person's state of total aspiration to the ultimate reality. The proposed concept focuses on the subjective component of the ultimate experience and can be used in religious studies, sociology, psychology and cultural studies.

Integral understanding focuses on three basic phenomena: individuality, nature of value and the meaning of freedom. Integral understanding includes four core competencies. The first is an understanding of ultimate universal meanings, expressed in different languages. The second is the ability to control emotional intelligence. The third is the ability to guide the will to a constructive goal. The fourth is the practical experience of working with humans.

Keywords: Joachim Wach; religious experience; value orientations; ultimate reality; ultimate orientations; integral understanding; emotional intelligence; subcultures; sociology of religion

\section{REFERENCES}

Buiakova, E. V. (2016) Teoreticheskie aspekty issledovaniia tsennostei. Kontsept, vol. 15, pp. 231-235 [online] Available at: http://e-koncept.ru/2016/86947.htm (accessed: 14.06.2018). (In Russ.).

Dobren'kov, V. I. (2011) Tsennostno-orientirovannaia sotsiologiia: problemnoe pole postneklassicheskoi metodologii. Moscow, Akademicheskii proekt. Publ.; Al'ma Mater. Publ. 565 p. (In Russ.).

Emel'ianenko, T. V. (2002) Problema perevoda sotsiologicheskikh terminov: na primere perevoda peremennykh T. Parsonsa. Sotsiologicheskie issledovaniia, no. 6, pp. 137-142. (In Russ.).

Kozlova, I. L. (2018) Kriterii religioznogo opyta v religiovedcheskoi kontseptsii Joachima Wacha. Religiovedenie, no. 1, pp. 103-117. (In Russ.).

Kozlova, I. L. (2015) Sotsiologiia religii Ioakhima Wacha. Vestnik Moskovskogo universiteta. Seriia 18: Sotsiologiia i politologiia, no. 4, pp. 183-200. (In Russ.).

Komarova, A. V. (2018) Subkul'tury $v$ dukbovnoi zhizni obshchestva: religiozno-nravstvennyi aspekt : dis. ... kand. filos. nauk: 09.00.14/ Komarova Anna Vladimirovna. Moscow. 179 p. (In Russ.). 
Krasikov, V. I. (1998) Iav' bespokoistva (predel'nye znacheniia chelovecheskogo susbchestvovaniia). Kemerovo, Kemerovskii gosudarstvennyi universitet. Publ. 170 p. (In Russ.).

Kuz'menkov, V. A. (2018) Ritualy kak faktory vozniknoveniia tsennostei. Sotsial'no-politicheskie nauki, no. 1 (fevral'), pp. 152-157. (In Russ.).

Leont'ev, D. A. (1999) Metodika predel'nykb smyslov (MPS): Metodicheskoe rukovodstvo. Moscow, Smysl. Publ. 36 p. (In Russ.).

Einstein, A. (1950) Out of My Later Years. New York, Philosophical Library. 282 p.

Tillich, P. (1951) Systematic Theology, Volume 1. Chicago, University of Chicago Press. 307 p.

Wach, J. (1944) Sociology of Religion. Chicago, University of Chicago Press. $\mathrm{x}+418 \mathrm{p}$. $234 \mathrm{p}$.

Wach, J. (1958) The comparative study of religions. New York, Columbia university press. xlviii +

Wach, J. (1951) Types of religious experience christian and non-christian. Chicago, University of Chicago Press. xvi +275 p.

Wilber, K. (2007) The Integral Vision. A Very Short Introduction to the Revolutionary Integral Approach to Life, God, the Universe, and Everything. Boston\&London, Shambala. 232 p.

Submission date: 10.08 .2018 .

Козлова Ирина Аьвовна - магистр религиоведения, старший преподаватель кафедры религиоведения Российского православного университета святого Иоанна Богослова. Адрес: 127473, Россия, г. Москва, пер. Чернышевского, д. 11А, стр. 1. Тел.: +7 (495) 626-22-25. Эл. адрес: irinakozlova2011@gmail.com Научный руководитель - А-р филос. наук, проф. В. В. Шмидт.

Kozlova Irina Lvovna, Master of Religious Studies, Senior Lecturer, Department of Religious Studies, Theologian`s Russian Orthodox University of St. John the Divine. Postal address: 11A, Bldg. 1, Chernyshevskogo Lane, Moscow, Russian Federation, 127473. Tel.: +7 (495) 626-22-25. E-mail: irinakozlova2011@gmail.com Scientific Adviser - W. V. Schmidt, Doctor of Philosophy, Professor. 